THE WABASH CENTER

JOURNAL ON TEACHING

BOOK REVIEW

\title{
Generous Thinking: A Radical Approach to Saving the University
}

\author{
Kathleen Fitzpatrick \\ Baltimore, MD: John Hopkins University Press, 2019 \\ (26o pages, ISBN 978-1-4214-02946-5, \$29.95)
}

Steven C. Ibbotson

Prairie Colleges
Reviewed By

In this stimulating book, Kathleen Fitzpatrick argues the university can and should be the context where the critical ability to engage in generous thinking is modelled and supportedfor the students and the communities that universities serve (5). Thus, in the opening pages she clearly defines generous thinking as "a mode of engagement that emphasizes listening over speaking, community over individualism, collaboration over competition, and lingering with ideas that are in front of us rather than continually pressing forward to where we want to go" (4). While this lofty goal and definition may seem idealistic, Fitzpatrick does a good job of consistently and pointedly addressing the personal and institutional challenges individual faculty members and universities face in aligning their policies and practices to the stated mission.

Interacting with a range of literature in each area, she describes the multifaceted challenges. Being generous in listening means not reacting or preparing a response to what is said, but paying attention, asking probing questions to hear further, and understanding values. Generous reading includes sharing texts both for pleasure and for learning, combining ethical engagement and empathy. In both listening and reading, mutuality must be present for true generosity-and thus learning-to happen. Sharing information generously has become increasingly more possible in the past three decades. Despite the various ways in which research and results have become more public, significant challenges remain in actually making information access equitable for the marginalized, whether socially, financially, or otherwise.

Yet listening, reading, and sharing information must be done in a way that does not foster competitiveness and elitism. In many ways each of these challenges are attitudinal, and yet within academia they have become a means of showing power. In discussing what it means to be "critical," the motivation for reading, and translation of content, Fitzpatrick exemplifies the generous thinking she proposes. She asserts a radical paradigm shift, contending "the university should focus less energy on educating for leadership and more on educating for community" (213). Fitzpatrick does not shy away from potential arguments against her proposals. Rather, she acknowledges legitimate concerns and confronts the selfdefeating result of many contentions.

For teachers of theology and religion, the Fitzpatrick's ideas are directly relevant because the ability to share expertise on various matters of faith in the public square is not only valuable in and of itself, but can build bridges to future students and supportive constituents, both in the immediate community and beyond. The concepts discussed bring to mind the example of my colleague who shares her academic work on Hebrew literature and presents tidbits in a short weekly YouTube feature. As discussed in this book, others use blogs or social media to share academic research in public-friendly language and formats, beyond historic "preaching” opportunities.

Generous Thinking would be useful for faculty at any school, no matter its size, for a faculty retreat or for administrator/ faculty dialogue as part of strategic planning or community engagement discussions. 